Acta Theriologica 41 (1): 59-72, 1996.

PL ISSN 0001-7051

\title{
Space use and activity in a mediterranean population of badgers Meles meles
}

\author{
Alejandro RODRÍGUEZ, Rosalía MARTÍN and Miguel DELIBES
}

Rodríguez A., Martín R. and Delibes M. 1996. Space use and activity in a mediterranean population of badgers Meles meles. Acta Theriologica 41: 59-72.

Activity, spatial ecology, and pattern of sett use of a mediterranean population of badgers Meles meles Linnaeus, 1758 are described. Data come from Doñana National Park (SW Spain) where a 1-year radio-tracking study and a 9-year capture-recapture study were carried out. Badger home ranges were spatially structured, territories having an average size that is the largest reported in the literature. There was a correlation between territory size and ecological variables reflecting food patch dispersion. It is suggested that badgers might set territory limits to include enough patches of rabbit burrows in the critical summer period of low rabbit abundance. Badgers were not strictly nocturnal, and showed decreased activity levels in winter. Activity levels were higher in badgers living in dry habitats, and in all badgers during the dry season. Both photoperiod and rabbit availability were suggested as factors influencing activity parameters like activity length or resting intervals during activity periods. Differences in the pattern of use of the main and secondary setts were found between reproductive females and other individuals.

Estación Biológica de Doñana, CSIC, Avda. María Luisa s/n, 41013 Sevilla, Spain

Key words: Meles meles, activity, space use, sett use, mediterranean environment

\section{Introduction}

The European badger Meles meles Linnaeus, 1758 is widely distributed throughout the Palaearctic, occurring in eurosiberian, mediterranean, and sub-arid environments (Corbet 1978, Neal 1986). Most aspects of badger ecology in the mediterranean are unknown. Instead work there has focused mainly on diet (Ciampalini and Lovari 1985, Pigozzi 1991, Rodríguez and Delibes 1992). These studies have shown how fruit and arthropods are the main components of the diet, in contrast with northern areas of Europe where other prey, mainly earthworms, are the staple food of the badger (Neal 1986, Roper 1994). Recently, Martín et al. (1995) have demonstrated that in Doñana, a mediterranean locality of southwestern Spain, badgers are feeding specialists on the youngest age class of rabbits Oryctolagus cuniculus.

Together with feeding specialization on rabbit kittens, a very low group size seems to be an additional special feature of the Doñana badger population. This has been suggested by the results of sett digging before the protection of the area 
in the 1960s. Gamekeepers dug many setts and rarely found more than two adult badgers per sett.

Several models attempting to explain the complex spatial grouping in badgers rely on prey characteristics such as dispersion, patchiness, richness within a patch or renewal rate (Woodroffe and Macdonald 1993). In addition, empirical evidence indicates that changes in the availability of preferred foods can strongly influence social organization and population density of badgers (Kruuk and Parish 1982, 1985, 1987). In Doñana, seasonal and habitat differences in the availability of rabbit kittens are well known (Martín et al. 1995). Rabbit reproduction almost stops during the dry season, between June and November (Delibes and Calderón 1979). Rabbit burrows are patchily distributed, being more abundant and less dispersed in humid habitats than in dry ones (Rogers and Myers 1979). The Resource Dispersion Hypothesis (RDH) (Kruuk 1978b, Macdonald 1983, Woodroffe and Macdonald 1993) predicts an increase in range size or, alternatively, a disruption of territoriality (Martín et al. 1995) for badgers living in dry habitats.

Activity is another aspect of behaviour that may be related to the type and availability of prey. Circadian activity cycles of carnivores are often related to prey behaviour (Kavanau 1971), and daily peaks should occur at the time when foraging is most rewarding (Vaughan 1986). However, activity patterns of badgers have received little attention. Neal (1986) summarized some work on badger activity, largely based on observations at sett entrances. This method has proved inadequate for parameters such as length of the activity period, because it is difficult to confirm individual identity of animals by sight (Harris 1982). Other interesting features of badger activity, such as occurrence and duration of resting between emergence and return to the sett (Harris 1982), also cannot be studied from observations at sett entrances (Bonnin-Laffargue and Canivenc 1961, Göransson 1983, Neal 1986). To some extent, badger activity has been studied in urban populations (Harris 1982, Cresswell and Harris 1988a, b), but it is poorly known in rural areas.

In this paper we describe the results of a one-year radio-tracking study on the spatial organization, movements, activity, and sett utilization in the badger population of the Doñana National Park. We also give capture-recapture data over a period of nine years to provide further information on group size and density. We test $\mathrm{RDH}$ predictions about the relationships between badger behaviour and the availability of rabbit kittens. Specifically, we expected a greater range size and a longer duration of activity for badgers occupying ranges where less productive habitats (dry sites) were dominant, because individuals would have had to forage on more widely dispersed patches of rabbit burrows to achieve the same minimal requirements of badgers living near the productive humid sites. We also expected a greater amount of activity in summer, when rabbit scarcity was higher.

\section{Study area}

The study area has been described by Martín et al. (1995), and more extensively by Allier et al. (1974). Briefly, it is a 2500 ha flat sandy area on the western border of the Guadalquivir river 
marshes, within the Doñana National Park, SW Spain. The climate is mediterranean, notably seasonal, with mild wet winters, and hot dry summers. There are four main habitat types. Xerophitic, open scrub is the dominant vegetation type, while denser scrub and seasonal lagoons are found in low-lying patches. Near the marsh border, vegetation cover is a mosaic of bracken, rush and pastures. Inland, pinewood substitutes for xerophitic scrub. Marshes and many lagoons dry out in summer, when they become firm ground. According to the degree of soil moisture, habitat types can be classified as 'humid' (dense scrub and pastures) or 'dry' (xerophitic scrub and pinewood). Agriculture has been absent for centuries and human disturbance is very low. Rabbit burrows concentrate mainly in the humid habitat types, ie marsh border, lagoon perimeters and low-lying sites, while they are rather dispersed in dry habitats (Rogers and Myers 1979).

\section{Material and methods}

\section{Sampling}

The radiotelemetry study was undertaken between February 1985 and April 1986. Badgers were captured with coil-spring traps (Woodstream Co., Pennsylvania) and snares. Traps were placed near badger setts and along trails where there were signs of badger activity. In addition, from 1983 to 1991 baited coil-spring traps and baited cage traps (Delibes and Beltrán 1986) were activated in the study area to catch lynx and other carnivore species, including badgers. In all 9 years, trapping was intensive from November to March (an average of 10 to 20 trap-nights, in several periods of up to 15 days each), and occasional during the rest of the year.

Badgers were anaesthetized using a mixture of ketamine and xylazine (Travaini et al. 1994). Sex, body measures, weight, reproductive condition and age, estimated from tooth wear (Harris et al. 1992), were recorded. The minimum age (yr) was estimated as 0 for juveniles, 1 for adults (males and non-breeding females), 2 for breeding females (Cheeseman et al. 1987), and 3 for badgers showing an intense tooth wear. Radio collars from different manufacturers (Biotrack, England; Wagener, Germany; AML, Finland), provided with an activity sensor, were attached to badgers before they were released near the site of capture. Details on trapping procedures and telemetry equipment have been reported elsewhere (Delibes and Beltrán 1986). Antenna break or transmitter failure forced short monitoring periods for some individuals. Badgers caught out of the study year were marked with coloured collars without a transmitter.

\section{Home range}

To estimate the home range size of badgers, radio-fixes were taken on days randomly selected within each month to ensure independence of data (Swihart and Slade 1985). On each radio-tracking day at least one fix was taken in the morning (preferably before sunrise) and an additional fix was recorded at night. Sometimes a second daytime fix was taken in the evening to detect a possible change in resting site. For each badger both total home range size and shape (all months combined), and monthly range size were estimated using the Minimum Convex Polygon method (Mohr 1947). Graphic representation of home range size vs number of fixes indicated that 25 fixes were enough to estimate monthly home range size. For total range size, the first asymptote was reached on average with 39 fixes $(S D=13$ ). The proportion of each of four main habitats (pinewood, scrubland, scrubland/grassland mosaic, and marsh) was estimated for each monthly range on a 1:10.000 habitat map (Allier et al. 1974).

\section{Movements}

Once a month each badger was radiotracked for a complete 24 hours taking a fix every hour. Minimum distances travelled between consecutive locations were calculated from a 1:10.000 map where triangulations were performed. Minimum distance travelled during an activity cycle was defined as the sum of distances between hourly consecutive fixes. 


\section{Activity}

Activity was recorded from radiocollar signal at random times while taking fixes for home range size estimation, and every hour during the $24 \mathrm{~h}$ sampling. Activity was also monitored even when fixes could not be taken. Activity data were grouped in two ways. First, all records were used to provide the frequency distribution of activity between daylight and night, these two periods being defined by the times of sunset and sunrise. Second, only records from the $24 \mathrm{~h}$ sampling were used to describe the pattern of activity, ie duration, continuity or discontinuity, and times of start and end of the activity periods.

\section{Social interactions}

When the proportion of home range overlap between badgers was large and stable over time, and sett sharing occurred, badgers were considered to be in the same group. The opposite was true for no or minimal range overlap. Social interactions during periods of activity were described from simultaneous $24 \mathrm{~h}$ monitoring of badgers living within the same range.

\section{Sett use}

Different setts were identified and the proportion of diurnal resting of each badger within each sett was calculated. The proportion of diurnal resting locations within the main and secondery setts was compared among individuals. In addition visits to other setts during the activity period as well as changes of sett during the inactivity period were recorded.

\section{Analyses}

Activity and space use data were compared between individuals living in different habitat types, and between seasons using pooled data, looking for the effects of spatial and seasonal varation of rabbit availability on badger behaviour. Data on rabbit distribution, abundance, reproductive pattern and mortality rate by badger predation were taken from previous studies in Doñana (Delbes and Calderón 1979, Rogers and Myers 1979, Villafuerte 1994).

Seasons were defined following Font (1983) as spring (Mar-May), summer (Jun-Aug), autumn (Sep-Nov), and winter (Dec-Feb). As sample sizes were small in autumn and winter, data from these seasons were often combined for analysis.

Approximation of proportions to a normal distribution was achieved through aresin transformation. Parametric procedures (two-tailed or one-tailed $t$-tests for two-sample hypothesis, sne-way ANOVA for multisample hypothesis, and regression analysis) were used to make individual and seasonal comparisons. Categorical data analyses were performed using contingency table statistics $\left(\chi^{2}\right.$-test, $G$-test, and Fisher exact test). The significance level used for all tests was 0.05 .

\section{Results}

\section{The badgers}

During the intensive study period only six adult badgers, four females and two males, could be caught. The same six badgers were the only individuals trapped in the study area between 1983 and 1986, after an estimated trapping effort of over 1800 trap-nights.

Table 1 shows the badgers' physical characteristics. All females had some kind of reproductive activity at the time of the capture. In late January, female 3 (F3) was pregnant and F4 was lactating. Another lactating female (F1) was examined on the 7th March, and F2 had developed nipples in early May but was not laciating. 
Table 1. Measures (in $\mathrm{mm}$ ) and weights (in $\mathrm{kg}$ ) of badgers in Doñana.

\begin{tabular}{cccccc}
\hline & $\begin{array}{c}\text { Head and } \\
\text { body length }\end{array}$ & $\begin{array}{c}\text { Tail } \\
\text { length }\end{array}$ & $\begin{array}{c}\text { Hind } \\
\text { foot }\end{array}$ & $\begin{array}{c}\text { Ear } \\
\text { length }\end{array}$ & Weight \\
\hline Males & & & & & \\
M1 & 705 & 180 & 108 & 50 & 8.20 \\
M2 & 750 & 174 & 115 & 50 & 8.60 \\
Females & & & & & \\
F1 & 595 & 163 & 104 & 45 & 6.35 \\
F2 & 650 & 160 & 105 & 45 & 7.90 \\
F3 & 660 & 166 & 100 & 40 & 8.71 \\
F4 & 700 & 156 & 104 & 46 & 7.96 \\
\hline
\end{tabular}

All females except F2 were old. F4 had cataracts in both eyes and was probably blind. Males M1 and M2 were captured in late February 1985 and late January 1986, respectively.

\section{Home range}

Individual ranges were drawn from a sample size of 385 fixes (Table 2). All animals were trapped near the border of their home ranges (Fig. 1). Range size varied greatly among individuals (Table 2): M1 and F3 had ranges between 150 and 400 ha. Range size of M1, however, doubled in summer because this badger

Table 2. The cumulative monthly range size (ha) of badgers in Doñana. N number of fixes, $\mathrm{N}^{*}$ - random daily fixes from which range sizes were drawn. Data from M2 not included owing to small number of fixes.

\begin{tabular}{|c|c|c|c|c|c|c|}
\hline & \multirow{2}{*}{ Month } & \multicolumn{5}{|c|}{ Individual } \\
\hline & & M1 & F1 & F2 & F3 & F4 \\
\hline \multirow[t]{9}{*}{1985} & Mar & 223 & 561 & & & \\
\hline & Apr & 242 & 688 & & & \\
\hline & May & 250 & 730 & 411 & & \\
\hline & Jun & 365 & 907 & 488 & & \\
\hline & Jul & 365 & 907 & 546 & & \\
\hline & Aug & 772 & 964 & 546 & & \\
\hline & Sep & 772 & 983 & 584 & & \\
\hline & Oct & 772 & 983 & & & \\
\hline & Nov & 772 & & & & \\
\hline \multirow[t]{4}{*}{1986} & Jan & & & 584 & 131 & 23 \\
\hline & Feb & & & 584 & 138 & 35 \\
\hline & Mar & & & 584 & 169 & 35 \\
\hline & Apr & & & & 169 & \\
\hline $\mathrm{N}$ & & 249 & 148 & 115 & 94 & 52 \\
\hline $\mathrm{N}^{*}$ & & 129 & 82 & 78 & 65 & 31 \\
\hline
\end{tabular}




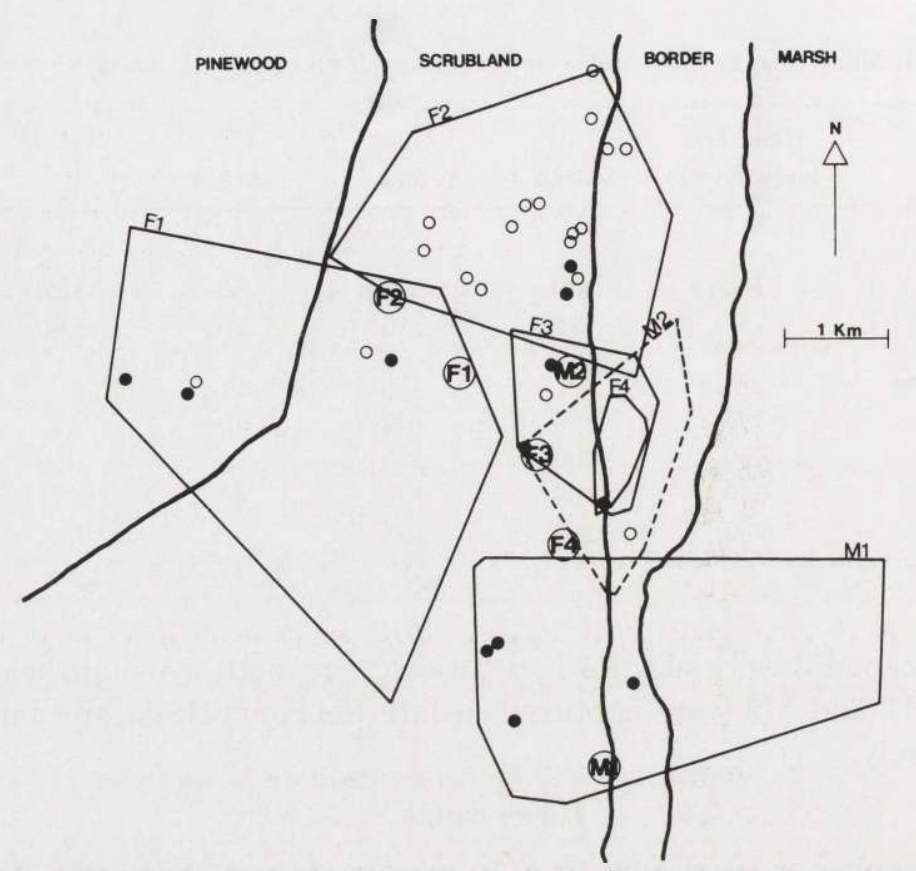

Fig. 1. The spatial organization of badgers in Doñana. Polygons indicate home range boundaries. Sites where badgers were trapped (big open circles), setts (black circles) and points of overground resting (small open circles) are shown. Broken line: the partial range of M2, for which not enough data were gathered.

sometimes foraged into the dry marsh, several $\mathrm{km}$ from the limits of its usual range during the rest of the year. Most of the observed variation was shown by the other females (Table 2). Excluding the summer home range expansion of M1, mean home range size was 525 ha.

Ranges of F3, F4 and M2 overlapped almost completely (> 75\% shared area; Fig. 1). F4 was trapped for the first time in March 1983, and recaptured twice in 1986, always within the limits of this shared range. For other badgers there was little or no overlap between pairs of neighbouring ranges $(<5 \%$ shared area). The proportion of locations within these small overlapping areas was very low $(1.2 \%$ of all fixes), and limits of neighbouring ranges were well adjusted, suggesting that marked badgers inhabited four different territories.

All individuals but F1 included in their ranges both scrubland and scrubland/ /grassland border, each habitat type accounting for at least $25 \%$ of their ranges sizes. In August, M1 frequented the dry marsh, a habitat available only in summer. The home range size of $\mathrm{F} 1$, the only badger settled exclusively on pinewood and scrubland, was at least $68 \%$ greater than the greatest range of the badgers living near the scrubland/grassland ecotone. A significant negative correlation existed between range size and the proportion of humid habitats in each range $(r=-0.925$, $p=0.024, n=5$; Fig. 2). 


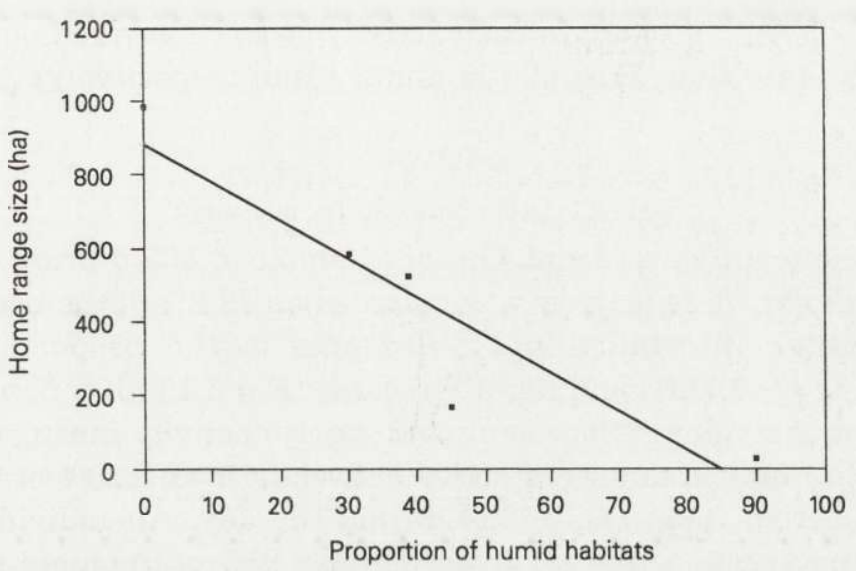

Fig. 2. The relationship between home range size of individual badgers and the arcsin transformed proportion of humid habitats contained in their ranges.

\section{Density and group size}

Detailed records of trapping effort were not taken, but we estimated a minimum of 600 trap-nights each year between 1983 and 1991 (an overall effort of about 5500 trap-nights). Between 1987 and 1991, 13 additional badgers were captured. Three juveniles and five adults were caught in 1989 and 1990, and two of these adults were recaptured twice in 1991, when other four old animals were trapped.

After 1987, 11 out of 13 badgers were caught just on the same territory boundaries estimated for the radiotagged badgers, suggesting that group territory limits may be stable over generations. Usually, two badgers of the same sex were not trapped in a same territory and in any pair of consecutive years (exceptions were F3 and F4, and two old females caught in 1991).

In all cases, new adult badgers were caught in a range when the estimated age of known holders of that home range was over 4 years old (more than 6 years old for $67 \%$ previous holders). Assuming that a badger's average lifespan is less than 3 years (Neal 1986), and that the probability of reaching an age of 4 years is very low (0.16; Cheeseman et al. 1987), the presence of new adult individuals in a territory might be associated with the death of previous tenants.

In the period 1989-1991, the maximum number of known adults was nine, yielding an estimated density of 0.36 adult badgers per $\mathrm{km}^{2}$. This figure was probably an underestimate because in some territories we saw one unmarked badger.

\section{Movements}

Differences between badgers in the average distance between consecutive locations were significant (ANOVA, $p<0.05$ ). F1 travelled greater distances $(\bar{x}=319 \mathrm{~m}, \mathrm{SD}=196, n=45)$ than $\mathrm{M} 1(\bar{x}=207 \mathrm{~m}, \mathrm{SD}=156, n=56$; one tailed $t$-test, $p<0.05$ ). Total daily distance travelled varied significantly among 
individuals (ANOVA, $p<0.05$ ). In each activity cycle $\mathrm{F} 1$ covered on average about a $50 \%$ more distance than M1 (3.2 km and $2.1 \mathrm{~km}$, respectively).

Activity

Time allocation between day and night

Badgers were mainly nocturnal. Out of a sample of 402 diurnal records, $87.3 \%$ indicated inactivity, while activity was recorded on $72.2 \%$ of the nocturnal sample ( $n=729$ records). Interindividual differences in the proportion of daytime $(F=9.76, \mathrm{df}=5, p<0.001)$ and nightly records $(F=5.15, \mathrm{df}=5, p<0.005)$ were significant. Two individuals showed almost strict inactivity during daylight $(<1 \%$ active records), 3 individuals were active between $5 \%$ and $20 \%$ of the times, and F1 was found active frequently (43\%) during the day. All individuals had high proportions of nocturnal activity. F1 was active $>95 \%$ of the night samples, while the other individuals fell in the $50-75 \%$ active record interval.

The proportions of active records during the day did not differ between seasons. However, there was a tendency for nocturnal active records to diminish in autumn and winter in comparison with the rest of the year (two-tailed $t, p<0.05$ ).

\section{Proportion of the night active}

This was defined as the amount of nocturnal activity divided by the night duration. Seasonal differences in the proportion of night with activity were highly significant $(F=12.75, \mathrm{df}=2, p<0.001)$. Badgers were active $96 \%$ of the summer nights, while in autumn and winter they spent an average of only $50 \%$ of the night active. The proportion of the night with activity in spring was $68 \%$, also significantly lower than the summer one (Tukey test, $p<0.05$ ). A significant negative correlation existed between the proportion of the night with activity and the night duration $(r=-0.612, p=0.012, n=16)$.

\section{Activity time length}

The average estimated length of the daily activity period was 8.2 hours $(\mathrm{SD}=2.1$, range: $3.0-11.3)$. The duration of the daily activity period did not vary significantly between individuals. Seasonal differences, however, were significant $(F=5.57, \mathrm{df}=2, p<0.02)$. Average activity length in summer was $9.7 \mathrm{~h}$, three hours longer than in autumn and winter $(6.2 \mathrm{~h})$. There was a positive relationship between activity time length and photoperiod length but correlation was not significant $(r=0.447, p=0.083, n=16$ ).

Noticeable interruptions of the activity period (namely resting events) occurred in $44 \%$ of the 24 -h monitoring periods. Resting duration varied between one and five hours (mean $1.72, \mathrm{SD}=1.3, n=7$ ).

\section{Sett use}

The number of setts used by badgers in each group territory was four or less (Fig. 1 and Table 3). Four out of five individuals were located in some sett for $90 \%$ or more days during their inactive period (Table 3). After excluding data from its 
Table 3. The number and utilization of setts during diurnal resting. $\mathrm{N}$ - days of observation, $\mathrm{S}$ - number of used setts, $\mathrm{O}$ - days in which badgers slept overground, $\% \mathrm{~S}$ - percent days sleeping in some sett. * breeding period excluded.

\begin{tabular}{lccrc}
\hline Individual & $\mathrm{N}$ & $\mathrm{S}$ & $\mathrm{O}$ & $\% \mathrm{~S}$ \\
\hline M1 & 85 & 4 & 4 & 95.3 \\
F1 & 32 & 3 & 3 & 90.6 \\
F2 & 50 & 3 & 16 & 68.0 \\
F3 & 59 & 4 & 2 & 96.6 \\
F4 & 27 & 1 & 0 & 100 \\
F2* & 24 & 3 & 16 & 33.3 \\
\hline
\end{tabular}

Table 4. The rate of sett use, expressed as days of use/days of control (× 100). S2-S4 secondary setts. * breeding period excluded.

\begin{tabular}{lcccc}
\hline Individual & $\begin{array}{c}\text { Main } \\
\text { sett }\end{array}$ & S2 & S3 & S4 \\
\hline M1 & 81.2 & 10.6 & 2.4 & 1.2 \\
F1 & 62.5 & 15.6 & 12.5 & \\
F2 & 52.0 & 12.0 & 2.0 & \\
F3 & 59.3 & 18.6 & 10.2 & 8.5 \\
F4 & 100 & & & \\
F2* & 25.0 & 4.2 & & 4.2 \\
\hline
\end{tabular}

breeding period, F2 showed an atypical behaviour, sleeping only 33\% days in some sett.

The rate of use was not the same for all setts within each range. Usually, each badger had a main sett, used on more than $50 \%$ of sampling days, and a variable number of secondary setts (Table 4). Rates of use of the main sett varied among individuals. This rate was maximum for F4 (a lactating female), and high for M1 (Table 4). On the other hand, during its non-breeding period, F2 had a rate of use of the main sett which was significantly less than that of any other individual $(G$-tests, $p<0.05) . F 4$ used its main sett more $(G$-tests, $p<0.02)$ than the other badgers. Data did not allow seasonal comparisons among rates of sett use.

The pattern of sett use denoted the sequence of diurnal resting sites over series of successive days. It was likely to find a badger using the same sett during two consecutive days in spring $(67 \%, n=45)$ and winter $(70 \%, n=83)$. However, in the non-breeding season (summer and autumn) this preference was less marked $(49 \%, n=49)$. These seasonal differences were not significant for both males and non-reproductive females, but were significant for females showing reproductive activity (Fisher test, $p<0.001$ ). In summer and autumn, females that bred in the previous spring used the same sett during successive days less than the other badgers $\left(\chi^{2}\right.$-test, $\left.p<0.05\right)$.

Excluding F2 that rarely used setts, and F4 that only used one sett, during the activity period badgers visited setts other than the one used for resting in the previous day. This behaviour was recorded in $71 \%$ of nights. Sometimes resting events took place in these visited setts.

M1 changed sett during the daylight period in 50\% days in which morning and evening fixes were taken, usually in July-August, always approaching the marsh border. Diurnal sett changes were not observed in other individuals $(n=17)$. Diurnal resting sites were outside the setts 33 times (13\%; pooled data). Fifty-six per cent diurnal locations outside the sett ocurred in summer months, when diurnal temperature reached highest values in the study area, and when exposure to ectoparasites was high overground (but probably also into the sett). 


\section{Interactions \\ Sharing of setts}

M1 and F1 were not observed sharing setts with other badgers. F2 did not either, but this female usually did not use setts out of the breeding season. On the other hand, M2, F3 and F4 shared the sett where F4 probably gave birth in January 1986. M2 and F3 shared a second sett within their common range, and M2 was captured near a third sett used by F3. Moreover, the three badgers slept together sometimes during daytime, as did M2 and F3 in the setts they shared. F3 and F4 were located simultaneously on 22 days: on 14 they rested together into the sett where F4 probably had its cubs, whereas on 8 days F3 was found in all the other known setts or sleeping overground.

Interactions during the activity period

Only one simultaneous 24-h monitoring period could be performed for M2, F3 and F4. That day M2 slept overground, while F3 and F4 stayed together in the sett. The time of emergence differed in one hour between the females. M2 visited the cubs' sett after females had emerged, and stayed there until F4 returned, four hours later. M2 finished his 12-hour activity period in a second sett. F3 visited a different sett briefly and, after activity for nine hours, joined F4 in the cubs' sett. The followed path was independent for each badger.

The few times badgers were located in overlapping areas with neighbouring ranges, the neighbour was usually far from the intruder. Once F2 was in the overlap area of the F1 range when F1 was only $200 \mathrm{~m}$ apart, but contact was not detected. Only one interaction with unmarked badgers was observed: in May 1985 F1 was seen near its main sett with an unknown individual, probably one of its cubs. Another unmarked badger was seen alone within the range of F2 in September 1985.

\section{Discussion}

The consistent low trapping success (19 badgers caught 24 times) relative to a high trapping effort (more than 5500 trap-nights throughout a 9-years period) indicates that badgers in Doñana were very scarce. Thus, our small badger sample might be a consequence of the very low density of this population.

The strict non-overlap between some home ranges and the temporal avoidance of neighbouring individuals, where slight overlap of their ranges occurred, suggests territoriality. The capture of all badgers at the border of their home ranges may indicate a territory patrolling behaviour, as well as increased trappability due to a more investigative behaviour near the range boundaries (Laundré and Keller 1983). In Doñana, we have found a high latrine concentration around some used setts (authors, unpubl. data). As main setts tended to be placed near the range boundaries, these latrines might have a territory-marking function. Moreover, ranges adjoined. Therefore, the spatial organization of badgers in Doñana appears 
structured in well defined territories, as it has been found for other populations in rural areas (Kruuk 1978a, Cheeseman et al. 1981, Kruuk 1989).

So far territoriality in badgers has been explained by the defence of two kinds of resource, food (Kruuk 1978b) and setts (Roper 1992, Doncaster and Woodroffe 1993). The sand of Doñana probably was not a limiting factor for digging, and sett excavation might have a rather low cost. On the other hand, rabbit kittens were a limited resource in summer and a territory probably had to encompass enough rabbit patches throughout the year. This is predicted by the RDH to account for temporal fluctuations in the availability of prey such as earthworms within each patch (Kruuk 1978b, Woodroffe and Macdonald 1993). Rabbit kittens are unable to leave the burrow and, therefore, they do not fluctuate in time as earthworms, ie on a scale of hours or days, but on a seasonal scale (Martín et al. 1995). From late autumn to early summer, rabbit kittens are permanently available in some patches and their abundance within a patch depends on both reproduction and predation rates, being badger predation responsible for as much as $26 \%$ of dug rabbit burrows (Villafuerte 1994). In summer, when rabbit reproduction decreases, most patches are probably depleted. In this season, M1 foraged sometimes in the dry marsh (when secondary prey increase slightly in the diet, Martín et al. 1995), probably looking for abundant anura or crayfish (Delibes and Adrián 1987) in isolated ponds.

Therefore, every year there is a critical period of young rabbit scarcity that could lead badgers to adjust the total size of their territory to these poor conditions, ie they might follow an obstinate strategy (von Schantz 1984). The apparent stable limits of territories over nine years, and their very large average size in Doñana (the highest reported in the literature) support this hypothesis (Woodroffe and Macdonald 1993).

The observed variation in range size may be also explained by rabbit patch dispersion (Rogers and Myers 1979). As predicted by the RDH, a significant negative correlation was found between range size and the proportion of humid habitat within ranges. Furthermore F1, the only marked badger which had its complete range within dry habitat, spent significantly more energy (she daily travelled more distance and spent more time active) than badgers living in humid habitats.

More than two adult individuals can live in a same territory. However, it was rare to catch two contemporary adult badgers of the same sex in the same territory. Although we lack definitive evidence, and no solid conclusion can be drawn about group size, our results were consistent with the hypothesis of a low group size, close to two adult badgers per group.

In Doñana some features of badger activity were similar to those found elsewhere (Bonnin-Laffargue and Canivenc 1961, Harris 1982, Neal 1986): badgers were mostly nocturnal, and their daily activity period started usually with or soon after dusk. Diurnal activity was not rare, in contrast to previous work (Harris 1982, Neal 1986). There was a general reduction of activity in winter, observed in Doñana as well as in Bristol (Cresswell and Harris 1988a, b). The effect of the photoperiod on this underlying pattern of activity is strong (Maurel and Boissin 
1983), but such pattern is a simplification of the great amount of variation found both between (Harris 1982, this study) and within populations (Cresswell and Harris 1988a). Combinations of several variables indicating photoperiod length, natural light levels, and weather have failed to explain more than $26 \%$ of the observed variance in quarterly activity levels of badgers (Cresswell and Harris 1988b). Similarly, combinations of up to 37 habitat variables have explained less than $18 \%$ of the observed variation in badger movement analysed by quarters (Cresswell and Harris 1988a). Alternatively, the feeding specialization of badgers and the pattern of prey availability might explain some activity results (Harris 1982, Cresswell and Harris 1988a, Martín et al. 1995).

In Doñana, one rabbit litter, with an average size of 3.9 and a weight per kitten of up to $80 \mathrm{~g}$ (Delibes and Calderón 1979), provides up to $443 \mathrm{kcal}$ (Aldama and Delibes 1990). This quantity is 1.8 times the individual daily energy requirements of badgers in Doñana (average weight $=7.95 \mathrm{~kg}$; Table 1), as calculated from the badger's basal metabolic rate (Iversen 1972). With this valuable prey, it is likely that the time needed by a badger to obtain enough food would be less than the time necessary to obtain an equivalent quantity of, for example, earthworms. Consistently, we have found frequent resting events within the activity period which have been associated with a decrease in the feeding rate, and interpreted as a result of satiation (Kruuk 1978b). The observed summer increase in activity length might correspond with a greater foraging effort, as rabbit litters are much more abundant from autumn to spring than in summer (Delibes and Calderón 1979).

Sometimes resting events can be due to social interactions or parental care in the sett, as is suggested by the interactions among F3, F4 and M2. However, in Doñana $50 \%$ of resting events took place out of the sett [27\% cases recorded in Bristol by Harris (1982), none reported by Kruuk (1978b)]. In Scotland, activity interruptions have not been observed [T. Parish, in Harris (1982)].

As elsewhere (Kruuk 1989), movements of members of the same social group were independent. Breeding females used a single sett, and covered shorter distances than other individuals, probably because of the constraint of lactation and care of offspring. In spring, when cubs emerge, females often rested each day in a different sett. The frequent use of different setts may have the double function of sett maintenance and, probably most importantly, social contacts, for instance, mutual squat-marking (Kruuk 1989), as we have observed in simultaneous monitoring. These interactions took place mainly during the inactive period, as nocturnal encounters seemed to be very short. Diurnal changes of sett by M1 might reflect a reduction in travel time to distant food patches at the beginning of the activity period.

F3 was pregnant when she was captured, but a few days later showed a low index of sett fidelity as expected in non-breeding behaviour. F4 lactated when captured, two days after F3 marking. In the following weeks F4 showed strict sett fidelity and F3 visited, and slept frequently, in the same sett. These observations suggest that F3 lost its cubs, and thereafter seemed to behave as a helper. Abortion caused by the stress of capture cannot be ignored as a possible cause of cub loss, 
but infanticide is more likely to be the explanation. Although two or more litters can be produced within a social group, infanticide by the dominant female of subordinate females cubs (Lüps and Roper 1990) has been proposed as one of the possible mechanisms which maintain a constant number of cubs in each social group, with independence of the number of adult badgers present (Kruuk 1989).

Acknowledgements: We are grateful to R. Laffitte, J. F. Beltrán, J. Aldama and L. Barrios for field assistance, and G. Crema for drawing the figures. The study was funded by the project PB-87/0405 of the Dirección General de Investigación Científica y Técnica. Personal support to AR was provided by CSIC and Junta de Andalucía studentships. We would like to thank C. L. Cheeseman, L. M. Rogers and T. J. Roper for helpful comments on earlier drafts and for improving the English.

\section{References}

Aldama J. J. and Delibes M. 1990. Some preliminary results on rabbit energy utilization by the Spanish lynx. Doñana, Acta Vertebrata 17: 116-121.

Allier C., González-Bernáldez F. and Ramírez-Díaz L. 1974. Mapa ecológico de la Reserva Biológica de Doñana. Consejo Superior de Investigaciones Científicas, Sevilla: 1-11.

Bonnin-Laffargue M. and Canivenc R. 1961. Étude de l'activité du blaireau européen (Meles meles L). Mammalia 25: 476-484. [In Spanish with English summary]

Cheeseman C. L., Jones G. W., Gallagher J. and Mallinson P. J. 1981. The population structure, density and prevalence of tuberculosis (Mycobacterium bovis) in badgers (Meles meles) from four areas in south-west England. Journal of Applied Ecology 18: 795-804.

Cheeseman C. L., Wilesmith J. W., Ryan J. and Mallinson P. J. 1987. Badger population dynamics in a high-density area. Symposia of the Zoological Society of London 58: 279-294.

Ciampalini B. and Lovari S. 1985. Food habits and trophic niche overlap of the badger (Meles meles L.) and the red fox (Vulpes vulpes L.) in a Mediterranean coastal area. Zeitschrift für Säugetierkunde 50: 226-234.

Corbet G. B. 1978. The mammals of the Palaearctic region: a taxonomic review. British Museum (Natural History), London: 1-314.

Cresswell W. J. and Harris S. 1988a. Ranging behaviour and home-range utilization in a suburban badger (Meles meles) population. Mammal Review 18: 37-49.

Cresswell W. J. and Harris S. 1988b. The effects of weather conditions on the movements and activity of badgers (Meles meles) in a suburban environment. Journal of Zoology, London 216: 187-194.

Delibes M. and Adrián M. I. 1987. Effects of crayfish introduction on otter Lutra lutra food in the Doñana National Park, SW Spain. Biological Conservation 42: 153-159.

Delibes M. and Beltrán J. F. 1986. Radio-tracking of six species of carnivores in the Doñana National Park, SW Spain. Mesogée 46: 113-120.

Delibes M. and Calderón J. 1979. Datos sobre la reproducción del conejo, Oryctolagus cuniculus (L.), en Doñana, S. O. de España, durante un año seco. Doñana, Acta Vertebrata 6: 91-99. [In Spanish with English summary]

Doncaster C. P. and Woodroffe R. 1993. Den site can determine shape and size of badger territories: implications for group-living. Oikos 66: 88-93.

Font I. 1983. Climatología de España y Portugal. Instituto Nacional de Meteorología, Madrid: 1-296.

Göransson G. 1983. Denning activity in Swedish badgers, Meles meles. Acta Zoologica Fennica 174: 179-181.

Harris S. 1982. Activity patterns and habitat utilization of badgers (Meles meles) in suburban Bristol: a radio tracking study. Symposia of the Zoological Society of London 49: 301-323.

Harris S., Cresswell W. J. and Cheeseman C. L. 1992. Age determination of badgers (Meles meles) from tooth wear: the need for a pragmatic approach. Journal of Zoology, London 228: 679-684. 
Iversen J. A. 1972. Basal energy metabolism of mustelids. Journal of Comparative Physiology 81: 341-344.

Kavanau J. L. 1971. Locomotion and activity phasing of some medium-sized mammals. Journal of Mammalogy 52: 386-403.

Kruuk H. 1978a. Spatial organization and territorial behaviour of the European badger Meles meles. Journal of Zoology, London 184: 1-19.

Kruuk H. 1978b. Foraging and spatial organisation of the European badger, Meles meles L. Behavioural Ecology and Sociobiology 4: 75-89.

Kruuk H. 1989. The social badger. Oxford University Press, Oxford: 1-155.

Kruuk H. and Parish T. 1982. Factors affecting population density, group size and territory size of the European badger, Meles meles. Journal of Zoology, London 196: 31-39.

Kruuk H. and Parish T. 1985. Food, food availability and weight of badgers (Meles meles) in relation to agricultural changes. Journal of Applied Ecology 22: 705-715.

Kruuk H. and Parish T. 1987. Changes in the size of groups and ranges of the European badger (Meles meles L.) in an area in Scotland. Journal of Animal Ecology 56: 351-364.

Laundré J. W. and Keller B. L. 1983. Trappability of coyotes relative to home range boundaries. Canadian Journal of Zoology 61: 1932-1934.

Lüps P. and Roper T. J. 1990. Cannibalism in a female badger (Meles meles): infanticide or predation? Journal of Zoology, London 221: 314-315.

Macdonald D. W. 1983. The ecology of carnivore social behaviour. Nature 301: 379-384.

Martín R., Rodríguez A. and Delibes M. 1995. Local feeding specialization by badgers (Meles meles) in a mediterranean environment. Oecologia 101: 45-50.

Maurel D. and Boissin J. 1983. Seasonal rythms of locomotor activity and thyroid function in male badgers (Meles meles L.) Journal of Interdisciplinary Cycle Research 14: 285-303.

Mohr C. O. 1947. Table of equivalent populations of North American small mammals. American Midland Naturalist 37: 223-249.

Neal E. 1986. The natural history of badgers. Croom Helm, Beckenham: 1-238.

Pigozzi G. 1991. The diet of the European badger in a Mediterranean coastal area. Acta Theriologica 36: 293-306.

Rodríguez A. and Delibes M. 1992. Food habits of badgers (Meles meles) in an arid habitat. Journal of Zoology, London 227: 347-350.

Rogers P. M. and Myers K. 1979. Ecology of the European wild rabbit, Oryctolagus cuniculus (L.), in Mediterranean habitats. Journal of Applied Ecology 16: 691-703.

Roper T. J. 1992. Badger Meles meles setts: architecture, internal environment and function. Mammal Review 22: 45-53.

Roper T. J. 1994. The European badger Meles meles: food specialist or generalist? Journal of Zoology, London 234: 437-452.

Schantz T., von 1984. Spacing strategies, kin selection, and population regulation in altricial vertebrates. Oikos 42: 48-58.

Swihart R. K. and Slade N. A. 1985. Influence of sampling interval on estimates of home-range size. Journal of Wildlife Management 49: 1019-1025.

Travaini A., Ferreras P., Aldama J. J., Fedriani J. M. and Delibes M. 1994. Chemical immobilization of wild badgers (Meles meles). Revue de Médicine Véterinaire 145: 577-580.

Vaughan T. A. 1986. Mammalogy. Saunders College Publishing, Flagstaff: 1-576.

Villafuerte R. 1994. Riesgo de predación y estrategias defensivas del conejo, Oryctolagus cuniculus, en el Parque Nacional de Doñana. Ph D thesis, University of Córdoba: 1-229.

Woodroffe R. and Macdonald D. W. 1993. Badger sociality - models of spatial grouping. Symposia of the Zoological Society of London 65: 145-169.

Received 24 April 1995, accepted 15 January 1996. 